Original Research Paper

\title{
Age-Dependent Variation of Telomere Length and DNA Damage in Chicken
}

\author{
${ }^{1}$ Maxim S. Makarenko, ${ }^{1}$ Alexander V. Usatov, ${ }^{2}$ Lyubov V. Getmantseva, \\ ${ }^{1}$ Vladimir A. Chistyakov, ${ }^{2}$ Aleksander I. Klimenko and ${ }^{2}$ Vyacheslav Vasilenko \\ ${ }^{I}$ Southern Federal University, Rostov-on-Don, 344006, Russia \\ ${ }^{2}$ Don State Agrarian University, Persianovski, 346493, Russia
}

\section{Article history}

Received: $10-10-2017$

Revised: 23-11-2017

Accepted: 14-12-2017

Corresponding Author:

Lyubov V. Getmantseva

Don State Agrarian University,

Persianovski, 346493, Russia

Email: ilonaluba@mail.ru

\begin{abstract}
Birds are unique models for molecular studies on aging processes and cellular senescence because of their slow rates of aging and comparatively long life spans among homoeothermic animals. The study aimed to examine the relative telomere length and amount of nuclear, mitochondrial DNA lesions in hens of different ages and to find out the correlation between these biomarkers of aging. The study was carried out on hens of crossbreed «High Sex Brown» of different age groups - 1, 75, $225,330,450$ days old. The measurements of telomeres and DNA damage were done in red cells of hens using quantitative PCR technique. We found out that the amount of telomeric DNA reduced significantly with age. Telomere length ratio to control group ( 1 day old) made up: $0.88 \pm 0.08$ for 75 days old, $0.73 \pm 0.07$ for 225 days old, $0.66 \pm 0.1$ for 330 -days old and $0.58 \pm 0.12$ for 450 days old. The amount of DNA lesions in both genomes had great, age-dependent increase. The relative quantity of lesions per 10 $\mathrm{kb}$ detected in the nuclear DNA were as follows: $0.17 \pm 0.19$ for 75 days old, $0.66 \pm 0.21$ for 225 days old, $1.02 \pm 0.33$ for 330 -days old and $1.48 \pm 0.45$ for 450 days old and the relative quantity of lesions in mtDNA were as follows: $0.11 \pm 0.06$ for 75 days old, $0.84 \pm 0.23$ for 225 days old, $1.18 \pm 0.3$ for 330 days old and $1.49 \pm 0.35$ for 450 days old. The results obtained are of fundamental interest for aging processes, as well as could have an economic value for poultry farming.
\end{abstract}

Keywords: Aging, Chicken, Telomere Length, DNA Lesions

\section{Introduction}

The aging processes are being widely investigated in diverse taxa (Gomes et al., 2010; Baudisch, 2012) and among vertebrates aging of birds is of particular interest. For instance, birds, on average, live three times longer than mammals of equivalent body weight (Holmes et al., 2001). Birds have the paradoxical long life expectancy and slow rates of aging as compare with mammals, especially, taking into account such features of avian physiology, that adversely affect lifespan: elevated body temperature (about $3^{\circ} \mathrm{C}$ higher than in mammals), rapid metabolism processes (2-2.5 times higher), high blood glucose content (2-4 times higher) (Holmes et al., 2001; Austad, 2011). Thus all these features make birds extremely interesting objects for studying the aging processes.
One of DNA structure parameters correlating with age is telomere length (Gomes et al., 2010). It has been found that telomere length of somatic cells decreases with age in various species of different taxa, for instance: Siberian sturgeon (Simide et al., 2016), turquoise killifish (Ocalewicz, 2013), nine-spine stickleback (Noreikiene et al., 2017), loggerhead sea turtle (Hatase et al., 2008), alligators (Scott et al., 2006; Xu et al., 2009) sand martins, dunlins (Pauliny et al., 2006), donkey, sheep, domestic cat (Gomes et al., 2010) and others. Many studies of avian telomere length variation with age were done on wild populations of birds (Pauliny et al., 2006; Criscuolo et al., 2009; Heidinger et al., 2012; Herborn et al., 2014). However, telomeres length has high interindividual variability and depends on many genetic and environmental factors (Mather et al., 2011; 
Paul, 2011), hence for more accurate investigations of avian telomere length should be used model objects with similar genotype and environmental conditions. One of a useful model organism for study avian aging processes, including telomere length changing, is chicken (Swanberg et al., 2010; Kim et al., 2011). It is also worth noting, that investigation of chicken telomere-based mechanisms even may be more relevant to human biology than similar studies on commonly used rodent model organisms such as the laboratory mouse, which somatic cells have constitutive telomerase expression throughout the lifespan (Swanberg et al., 2010). Another molecular hallmark of aging is DNA damage. There is no doubt that DNA lesions are accumulating with age (Takubo et al., 2010). However, the rate of DNA lesions accumulation could vary widely in different cell types (Castro et al., 2012; Sohn et al., 2012) and differ between species (Meyer et al., 2007; Hunter et al., 2010). The amount of DNA damage also significantly depends on the type of genome: nuclear or mitochondrial (Wang et al., 2010). Age-dependent variations of DNA lesions have been studied predominantly in mammals - rats (Hamilton et al., 2001), mice (Wang et al., 2009), rhesus monkeys (Castro et al., 2012), human cells (Wang et al., 2010), as well as invertebrate animal models - nematode (Meyer et al., 2007) and fruit fly (Edman et al., 2009). But there is a lack of similar research on birds. The study aimed to examine the relative telomere length and the amount of nuclear, mitochondrial DNA lesions in hens of different ages and to find out the correlation between these biomarkers of aging.

\section{Materials and Methods}

\section{Husbandry and Sample Collection}

The study was carried out on hens of crossbreed «High Sex Brown». «High Sex Brown» is highly performance crossbreed, with average hen-day egg production $80 \%$ and egg mass $50 \mathrm{~g}$. The birds were maintained in the poultry cage systems - EURODENTParent (Big Dutchman (Germany)) with the microclimate conditions which are recommended by the manufacturer of High Sex Brown crossbreed: The temperature $-20^{\circ} \mathrm{C}$, the humidity- $68 \%$ and light/dark cycles-9/15 h with the light intensity of 5 lux. The hens were fed with standard mixed fodder, which composition is presented in Table 1 .

For research, we used blood samples from female chickens of different age: 1, 75, 225, 330 and 450 days old. 25 blood samples from each age group have were collected in heparinized tubes and centrifuged. Separated fractions of red cells were frozen in liquid N2 and then stored at $-80^{\circ} \mathrm{C}$ until DNA extraction.
Table 1: The composition of feed ingredients

\begin{tabular}{ll}
\hline Item & Amount \% \\
\hline Wheat & 15,95 \\
Corn & 45,00 \\
Soybean meal, 46\% CP & 11,50 \\
Sunflower meal, 36\% CP & 14,70 \\
Sunflower oil & 1,68 \\
DL-Methionine (99\%) & 0,11 \\
Fine limestone & 9,10 \\
Monocalcium phosphate & 1,10 \\
Sodium chloride & 0,26 \\
Sodium sulfate & 0,10 \\
Vitamin and mineral premix & 0,50 \\
\hline
\end{tabular}

\section{DNA Extraction and Polymerase Chain Reaction Amplification}

DNA extraction was performed from $40 \mathrm{uL}$ of red blood cells fraction with spin column-based nucleic acid extraction kit - K-Sorb kit (Syntol, Russia). All the DNA isolation steps were done according to the manufacturer's instruction. The purity of the DNA was measured using NanoDrop 2000 (Thermo Fisher Scientific, USA). DNA quantity was measured using fluorometer QuantiFluorST (Promega, USA) and QuantiFluor dsDNA System (Promega, USA).

We used the method of quantitative PCR for measuring relative telomere length as described Heidinger et al. (2012) with modifications. Briefly, the relative telomere length of each sample was measured by determining comparative quantitation $(\Delta \mathrm{Ct})$ of telomere repeat copy number ( $\mathrm{Ct}$ telomere) to single control gene copy number (Ct GAPDH) in each sample. Glyceraldehyde-3-phosphate dehydrogenase (GAPDH) was used as the single control gene. Then the fold changes $(\Delta \Delta \mathrm{Ct})$ relative to a reference value (mean $\mathrm{dCT}$ 1 day old group) was calculated. The PCR efficiency has been also taken into account. The amplification of telomeric regions was carried out using standard primers for vertebrates' telomeres: Tellb (5'-CGG TTT GTT TGG GTT TGG GTT TGG GTT TGG GTT TGG GTT3), Tel2b (5'-GGC TTG CCT TAC CCT TAC CCT TAC CCT TAC CCT TA CCC T-3) (Heidinger et al., 2012; O'Callaghan and Fenech, 2011) and for GAPDH amplification were used own developed primers with following sequences: 5'- CAT CAA ATG GGC GGA TGC AG-3' (GAPDH_F), 5'-GCA CCA GCA ATC CTT TTC CC-3' (GAPDH_R_119). Each Real-time PCR reaction was performed in triplicate using $15 \mathrm{ng}$ of extracted DNA, $0.2 \mathrm{uM}$ of forward and reverse primers and RT-PCR kit with EvaGreen dye (Syntol, Russia) on CFX96 Detection System (Bio-Rad, USA). The PCR conditions were as follows: Initial activation of the TaqDNA-Polymerase for $3 \mathrm{~min}$ at $95^{\circ} \mathrm{C}$, followed by 30 cycles of $10 \mathrm{sec}$ denaturation at $95^{\circ} \mathrm{C}$, annealing for 15 sec at $60^{\circ} \mathrm{C}$ and extension for $1 \mathrm{~min}$ at $72^{\circ} \mathrm{C}$.

For measuring of mitochondrial DNA (mtDNA) and nuclear DNA (nDNA) damage, the method based on 
endpoint quantitative PCR was used (Santos et al., 2002). The principle of this technique is that lesions present in the DNA (oxidized bases, thymine dimers, etc.) block the progression of polymerase on the template and results in a decrease of PCR products. Analysis of long PCR products allows increasing the sensitivity of such assay substantially. The amplification of long PCR products was performed with own developed primers: MT F (5'-ACC TTA GCC ATC ATC CCC CT-3') and MT R 100700 (5'-GGG TTG GGT TGT CGA CTG AA-3') for mtDNA; GAPDH_F and GAPDH_R_10040 (5'-CTG TGG GGT TGG CA $\bar{C}$ AAA AG -3') for $\bar{n}$ DNA. The length of amplicons made up $10070 \mathrm{bp}$ and 10040, respectively. It is also important to note that GC content for both PCR products was similar: $46.7 \%$ for mtDNA amplicon and $47.9 \%$ for nDNA amplicon. But the part of coding DNA in mitochondrial PCR product is ten times higher. For long PCR we used $15 \mathrm{ng}$ of DNA, $0.4 \mathrm{uM}$ of forward and reverse primers and LongAmp Taq PCR Kit (New England Biolabs, UK). The PCR conditions were as follows: Initial denaturation for $1 \mathrm{~min}$ at $95^{\circ} \mathrm{C}$, followed by $27-28$ cycles of $10 \mathrm{sec}$ denaturation at $95^{\circ} \mathrm{C}$, annealing for $30 \mathrm{sec}$ at $59^{\circ} \mathrm{C}$ and elongation for $9 \mathrm{~min}$ at $65^{\circ} \mathrm{C}$, finally extension step for $15 \mathrm{~min}$ at $65^{\circ} \mathrm{C}$. For mtDNA amplification, 27 cycles of PCR were used and 28 cycles - for nuclear. The quantity of PCR products was measured in three repetitions using fluorescent dyes analogically to DNA quantification. Although the initial amount of total DNA in each PCR sample was the same, the $\mathrm{mtDNA} / \mathrm{nDNA}$ ratio could vary. Therefore, the addition normalization of template copy number was made. For standardization copy number, the RT-PCR of short amplicons with the same forward primers (MT_F, GAPDH_F) was done.
The reverse primers for short amplicons were MT_R_272 (5-CAG TGA TTA GGG AGG AGC CTT G-3) and GAPDH_R_119. According to data of RT-PCR the normalization coefficient was calculated as $1+\mathrm{E}^{\wedge} \mathrm{Ct}$ sample - mean $\mathrm{Ct}$, where $\mathrm{E}=\mathrm{PCR}$ efficiency. The efficiency of PCR was calculated using standard curves. paper is one part of the entire proceedings, not an independent document. Please do not revise any of the current designations.

\section{Statistical Analysis}

Statistical analysis was released using R-studio version 3.4.1. The Shapiro-Wilk test was used to check the normality of data. For data comparison, Student's Ttest and Mann-Whitney U-test were done. For all possible pairwise comparisons, the Tukey method also was used. The correlation tests were done using Pearson and Spearman correlation coefficients. Differences were considered statistically significant at $\mathrm{p}<0.05$.

\section{Results}

The results of telomere length measurement by qPCR revealed the correlation between birds age and relative telomere length. $\mathrm{dCt}(\mathrm{Ct}$ Tel-Ct GAPDH) values were as follows: 1 day old $7.5 \pm 0.4 ; 75$ days old $6.6 \pm 0.7 ; 225$ days old $5.5 \pm 0.5 ; 330$-days old $4.9 \pm 0.7 ; 450$ days old $4.3 \pm 0.9$. Thus telomere length declined with age. The data of telomere length ratio ( $\Delta \Delta \mathrm{Ct}$ values), which represent the variation of telomeres in 75-450 days old groups to mean value of control group (1 day old), are presented in Fig. 1. Such a figure more clearly shows the change coefficient in telomere length which make up: $0.88 \pm 0.08$ for 75 days old, $0.73 \pm 0.07$ for 225 days old, $0.66 \pm 0.1$ for 330 -days old and $0.58 \pm 0.12$ for 450 days old.

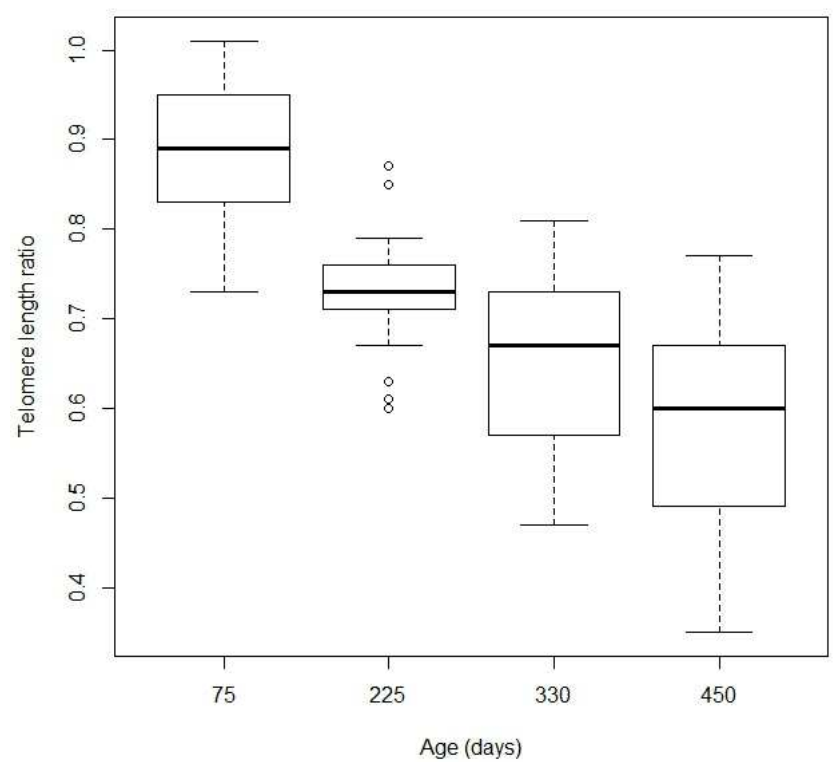

Fig. 1: The relationship between a ratio of telomere length of the control group mean value to age groups 


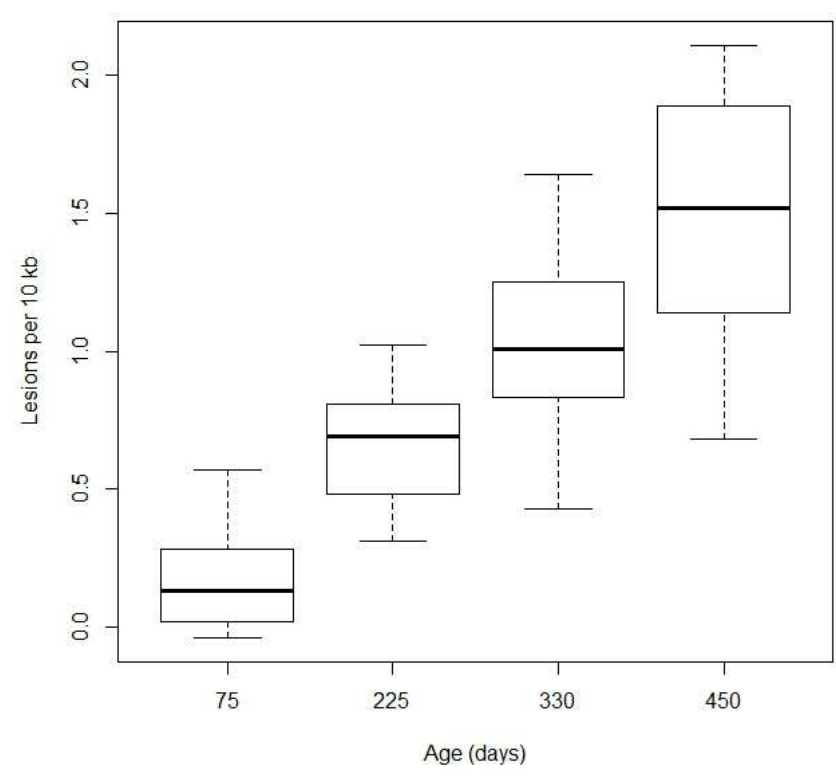

Fig. 2: The relative amount of lesions per $10 \mathrm{~kb}$ detected in the nuclear DNA (with normalization of mtDNA copy number)

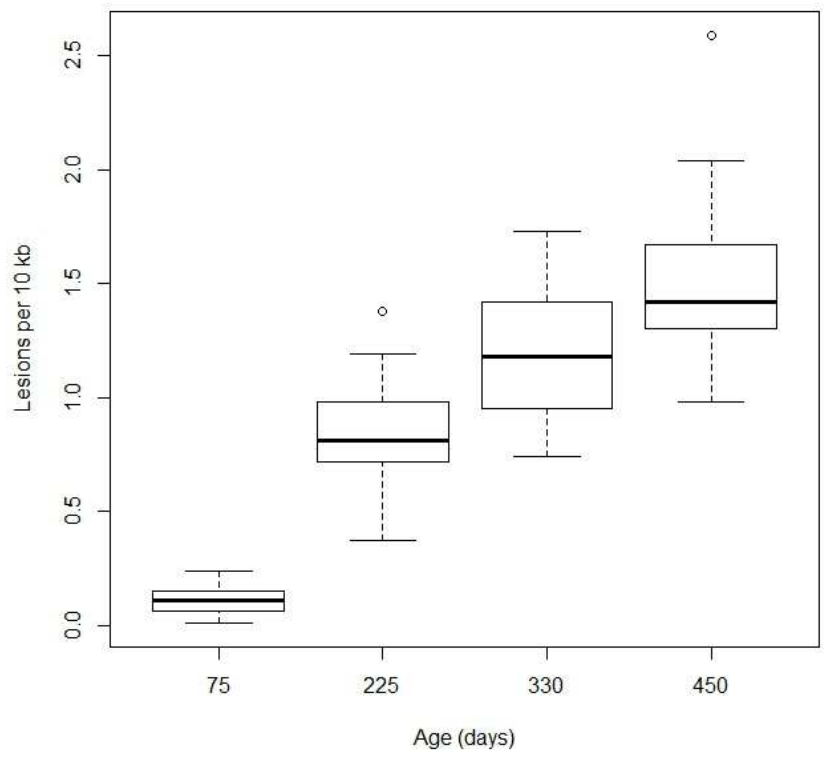

Fig. 3: The relative amount of lesions per $10 \mathrm{~kb}$ detected in the mitochondrial DNA (with normalization of copy nDNA number)

Noticeable that, with increasing age, the relative standard deviation is rising from $9.2 \%$ (75, 255 days) to $14.8 \%$ (330 days) and $19.8 \%$ (450 days). The amount of nuclear and mitochondrial DNA damage of $75,225,330,450$ days old relative to control (mean value of 1 day old group) are presented in Fig. 2 and 3 , respectively.

The relative quantity of lesions per $10 \mathrm{~kb}$ detected in the nuclear DNA were as follows: $0.17 \pm 0.19$ for 75 days old, $0.66 \pm 0.21$ for 225 days old, $1.02 \pm 0.33$ for 330 -days old and $1.48 \pm 0.45$ for 450 days old and the quantity of lesions in mtDNA were as follows:
$0.11 \pm 0.06$ for 75 days old, $0.84 \pm 0.23$ for 225 days old, $1.18 \pm 0.3$ for 330 -days old and $1.49 \pm 0.35$ for 450 days old. According to received data, the amount of DNA lesions in both genomes (mitochondrial and nuclear) increased with age. Opposite to telomere length data, in both types of DNA lesions, the relative standard deviation was about equal in each age group except 75 days old group. All received data of telomere length, nDNA and mtDNA lesions relative to control are summarized in Table 2. The information about a difference of parameters between two consecutive age groups is also presented in Table 2 . 
Table 2: Telomere length, nuclear and mitochondrial DNA lesions in chicken different age groups relative to control (1 day old group)

\begin{tabular}{|c|c|c|c|c|}
\hline Age in days & Mean value & Standard deviation & The ratio value $\% *$ & Test type, $\mathrm{P}$ value \\
\hline \multicolumn{5}{|c|}{ Relative telomere length } \\
\hline 75 & 0.88 & 0.08 & - & - \\
\hline 225 & 0.73 & 0.07 & $16.9 \%$ & T-test, $6.774 \mathrm{e}-09$ \\
\hline 330 & 0.66 & 0.10 & $10.6 \%$ & T-test, 0.001999 \\
\hline 450 & 0.58 & 0.12 & $11.5 \%$ & T-test, 0.01387 \\
\hline \multicolumn{5}{|c|}{ Relative amount of lesions per $10 \mathrm{~kb}$ detected in the nuclear DNA } \\
\hline 75 & 0.17 & 0.19 & - & - \\
\hline 225 & 0.66 & 0.21 & $390 \%$ & U-test, $6.856 \mathrm{e}-08$ \\
\hline 330 & 1.02 & 0.33 & $154 \%$ & U-test, 0.0001371 \\
\hline 450 & 1.48 & 0.45 & $145 \%$ & U-test, 0.0008445 \\
\hline \multicolumn{5}{|c|}{ Relative amount of lesions per $10 \mathrm{~kb}$ detected in the mitochondrial DNA } \\
\hline 75 & 0.11 & 0.06 & & \\
\hline 225 & 0.84 & 0.23 & $770 \%$ & U-test, $1.398 \mathrm{e}-09$ \\
\hline 330 & 1.18 & 0.30 & $140 \%$ & U-test, 0.0001603 \\
\hline 450 & 1.49 & 0.35 & $127 \%$ & U-test, 0.003082 \\
\hline
\end{tabular}

\section{Discussion}

Telomere length reduction is associated with wide range of genetic and environmental factors including sex, body size, reproduction, life stress, infection and chronic diseases (Paul, 2011). Consequently, investigations of human telomeres have controversial results in using telomere length as an accurate biological indicator of age (Mather et al., 2011; Boonekamp et al., 2013). However, in our study, there is a significant correlation between telomere length and hens age from 1 up to 450 days. The decrease of telomeres with age has been found in many other bird species studies: Sand martins, dunlins (Pauliny et al., 2006), alpine swift (Criscuolo et al., 2009), zebra finch (Heidinger et al., 2012), European shags (Herborn et al., 2014) and chicken (Kim et al., 2011). However, we used a qPCR technique for telomere length measurements and the obtained data are comparable with Kim et al. (2011) research of chicken telomere length in 10-80 weeks age hens. In both studies, the most significant reduction of telomeres is observed in puberty period and a start of laying eggs stage 75-225 days in our research and 20-30 weeks. It should be noted that zebra finches have the most accelerated telomere shortening in the first year of life when they are engaging in reproduction (Heidinger et al., 2012). However, comparing another study (Kim et al., 2011) with current research, the lower telomere shortening ratio between age groups was discovered. In 75-225 days old groups we detected $17 \%$ decrease of telomere length as well as in 10-30 weeks age groups (Kim et al., 2011) the difference was 38\% and the reduction ratio of 225-330 days and 30-50 weeks made up 11 and 15\%, respectively. Nevertheless, 330450 days old and 50-70 weeks age groups had more similar telomere length decrease ratio 12 and $14 \%$. Such variability may be explained by using different techniques (IQ FISH, qPCR) as well as various blood cells (lymphocytes, red blood cells). It should be noted that genetic factor such as breed could also play a role in telomere length, especially taking into account the difference in productivity of breeds (Sohn and Subramani, 2014). It is important to highlight that we first used 1 day old chicks as a control group, which in turn almost impossible be done in age studies on birds from wild populations for ethical reason.

The association of nuclear and mitochondrial DNA damage with age has also been detected. While telomere reduction in each subsequent age group was within 12$17 \%$, the relative increase of DNA lesions was much higher (1.25-7.7 fold). The largest change, as in the case of a decrease in telomere length, is observed in hens of 75-225 days old. The increase in these age period was 7.7 fold for mtDNA and 3.9 for $\mathrm{nDNA}$ and the subsequent increase ratio was $1.25-1.5$ fold.

Meanwhile, the association between age and telomere length, mtDNA, nDNA lesions was observed both correlation tests (Pearson and Spearman correlation coefficients) point out that the investigated parameters are changing independently. So agedependent telomere length decrease is not associated with mtDNA and nDNA damage. As well as mtDNA and nDNA lesions accumulate independently, although, they have the similar trend to increase with age. It should be highlighted that the data obtained are actual for normal conditions. There are no doubts that in oxygen stress-induced conditions the increased mtDNA damage could be a reason for extra reactive oxygen species, which in turn have a significant impact on cellular senescence, including telomeres shortening (Passos et al., 2007).

The most impressive result was gained while analyzing the relative amount of lesions in mtDNA and nDNA. Mean values of mtDNA and nDNA lesions in the 
same age group were similar and have no significant difference, except 225 days old group wherein less damaged (on 21\%) was nDNA. Age-dependent or induced DNA damage are 2-3 fold higher in mammalian mitochondrial DNA then in nuclear DNA (Wang et al., 2010; Hamilton et al., 2001). This argument is also confirmed on other organisms Caenorhabditis elegans (Meyer et al., 2007), Danio rerio (Hunter et al., 2010). Although our research data are opposite to other organisms' studies, the features of avian physiology could explain such a paradox. Compared with mammals the birds have much more efficient mitochondrial transport of electrons, which significantly (up to 10 times) reduces the generation of ROS (Montgomery et al., 2012). So the avian mtDNA is less damaged by ROS, which results in total mtDNA lesions decrease. Summarizing, the assumption could be made - the chicken rate of mtDNA and nDNA lesions are relatively equal throughout their life period.

Chicken telomere length, mtDNA and nDNA lesions have significant dependents on age and can be used as an effective age-marker. The age-associated changes of chicken relative telomere length, mtDNA and nDNA lesions varying independently. Unlike mammal species, the chicken had similar DNA lesions rates in both mitochondrial and nuclear genomes for lifespan. The results obtained are of fundamental interest for aging processes, as well as could have an economic value for poultry farming.

\section{Conclusion}

Chicken telomere length, mtDNA and nDNA lesions have significant dependents on age and can be used as an effective age-marker. The age associated changes of chicken relative telomere length, mtDNA and nDNA lesions varying independently. Unlike many mammal species, chicken have similar DNA lesions rates in both mitochondrial and nuclear genomes for lifespan. The results obtained are of fundamental interest for aging processes, as well as could have an economic value for poultry farming.

\section{Funding Information}

This research was supported by Russian Science Foundation project no.16-16-04032

\section{Author's Contributions}

Maxim S. Makarenko and Aleksander V. Usatov: Designed and performed experiments and wrote the paper.

Lyubov V. Getmantseva and Vladimir A. Chistyakov: Developed analytical tools and analyzed data.

Aleksander I. Klimenko and Vyacheslav Vasilenko: Collected and analyzed data.

\section{Ethics}

This article is original and contains unpublished materials. The corresponding author confirms that all of the other authors have read and approved the manuscript and no ethical issues involved.

\section{References}

Austad, S.N., 2011. Candidate bird species for use in aging research. ILAR J., 52: 89-96. PMID: 21411861

Baudisch, A., 2012. Birds do it, bees do it, we do it: Contributions of theoretical modelling to understanding the shape of ageing across the tree of life. Gerontology, 58: 481-489.

DOI: $10.1159 / 000341861$

Boonekamp, J.J., M.J. Simons, L. Hemerik and S. Verhulst, 2013. Telomere length behaves as biomarker of somatic redundancy rather than biological age. Aging Cell, 12: 330-332. DOI: 10.1111/acel.12050

Castro, M.R., E. Suarez, E. Kraiselburd, A, Isidro and J. $\mathrm{Paz}$ et al., 2012. Aging increases mitochondrial DNA damage and oxidative stress in liver of rhesus monkeys. Exp. Gerontol., 47: 29-37. DOI: $10.1016 /$ j.exger.2011.10.002

Criscuolo, F., P. Bize and L. Nasir, 2009. Real-time quantitative PCR assay for measurement of avian telomeres. J. Avian Biol., 40: 342-347. DOI: 10.1111/j.1600-048X.2008.04623.x

Edman, U., A.M. Garcia, R.A. Busuttil, D. Sorensen and M. Lundell et al., 2009. Lifespan extension by dietary restriction is not linked to protection against somatic DNA damage in Drosophila melanogaster. Aging Cell, 8: 331-338. DOI: $10.1111 /$ j.1474-9726.2009.00480.x

Gomes, N.M.V., J.W. Shay and W.E. Wright, 2010. Telomere biology in Metazoa. FEBS Lett., 584: 3741-3751. DOI: 10.1016/j.febslet.2010.07.031

Hamilton, M.L., H. Van Remmen, J.A. Drake, H. Yang and Z.M. Guo et al., 2001. Does oxidative damage to DNA increase with age? Proc. Natl. Acad. Sci. USA, 98: 10469-10474.

DOI: $10.1073 /$ pnas. 171202698

Hatase, H., R. Sudo, K.K. Watanabe and T. Kasugai, 2008. Shorter telomere length with age in the loggerhead turtle: A new hope for live sea turtle age estimation. Genes Genet. Syst., 83: 423-426. DOI: $10.1266 /$ ggs.83.423

Heidinger, B.J., J.D. Blount, W. Boner, K. Griffiths and N.B. Metcalfe et al., 2012. Telomere length in early life predicts lifespan. Proc. Natl. Acad. Sci. USA, 109: 1743-1748. DOI: 10.1073/pnas. 1113306109 
Herborn, K.A., B.J. Heidinger and W. Boner, 2014. Stress exposure in early post-natal life reduces telomere length: An experimental demonstration in a long-lived seabird. Proc. R. Soc.., 281: 20133151. DOI: $10.1098 /$ rspb.2013.3151

Holmes, D.J., R. Flückiger and S.N. Austad, 2001. Comparative biology of aging in birds: An update. Exp. Gerontol., 36: 869-883. PMID: 11295520

Hunter, S.E., D. Jung, R.T. Di Giulio and J.N. Meyer, 2010. The QPCR assay for analysis of mitochondrial DNA damage, repair and relative copy number. Methods, 51: 444-451.

DOI: $10.1016 /$ j.ymeth.2010.01.033

Kim, Y.J., V.K. Subramani and S.H. Sohn, 2011. Age prediction in the chickens using telomere quantity by quantitative fluorescence in situ hybridization technique. Asian-Australas J. Anim. Sci., 24: 603-609. DOI: 10.5713/ajas.2011.10187

Mather, K.A., A.F. Jorm, R.A. Parslow and H. Christensen, 2011. Is telomere length a biomarker of aging? A review. J. Gerontol. Biol. Sci. Med. Sci., 66: 202-13. DOI: 10.1093/gerona/glq180

Meyer, J.N., W.A. Boyd, G.A. Azzam, A.C. Haugen and J.H. Freedman et al., 2007. Decline of nucleotide excision repair capacity in aging Caenorhabditis elegans. Genome Biol., 8: R70-R70.

DOI: $10.1186 / \mathrm{gb}-2007-8-5-\mathrm{r} 70$

Montgomery, M.K., A.J. Hulbert and W.A. Buttemer, 2012. Does the oxidative stress theory of aging explain longevity differences in birds? II. Antioxidant systems and oxidative damage. Exp. Gerontol., 47: 203-210. DOI: 10.1016/j.exger.2011.11.014

Noreikiene, K., A. Kuparinen and J. Merilä, 2017. Age at maturation has sex- and temperature-specific effects on telomere length in a fish. Oecologia, 20: 1-11. DOI: $10.1007 / \mathrm{s} 00442-017-3913-5$

O'Callaghan, N. and M.A. Fenech, 2011. Quantitative PCR method for measuring absolute telomere length. Biol. Proc. Online, 13: 3-3. DOI: $10.1186 / 1480-9222-13-3$

Ocalewicz, K., 2013. Telomeres in fishes. Cytogenet. Genome Res., 141: 114-125.

DOI: $10.1159 / 000354278$

Passos, J.F., G. Saretzki and T. von Zglinicki, 2007. DNA damage in telomeres and mitochondria during cellular senescence: Is there a connection? Nucleic Acids Res., 35: 7505-7513. DOI: 10.1093/nar/gkm893

Paul, L., 2011. Diet, nutrition and telomere length. J. Nutr. Biochem., 22: 895-901.

DOI: $10.1016 /$ j.jnutbio.2010.12.001

Pauliny, A., R.H. Wagner, J. Augustin, T. Szep and D. Blomqvist, 2006. Age-independent telomere length predicts fitness in two bird species. Mol. Ecol., 15: 1681-1687. DOI: $10.1038 /$ ncb1108-1241
Santos, J.H., B.S. Mandavilli and B. Van Houten, 2002. Measuring oxidative mtDNA damage and repair using quantitative PCR. Meth. Mol. Biol., 197: 159-176. DOI: 10.1385/1-59259-284-8:159

Scott, N.M., M.F. Haussmann, R.M. Elsey, P.L. Trosclair and C.M. Vleck, 2006. Telomere length shortens with body length in alligator mississippiensis. Southeast Nat., 5: 685-692.

DOI: $\quad 10.1656 / 1528-7092(2006) 5$ [685:TLSWBL]2.0.CO;2

Simide, R., F. Angelier, S. Gaillard and A. Stier, 2016. Age and heat stress as determinants of telomere length in a long-lived fish, the Siberian sturgeon. Physiol. Biochem. Zool., 89: 441-447. DOI: $10.1086 / 687378$

Sohn, S.H., V.K. Subramani, Y.S. Moon and I.S. Jang, 2012. Telomeric DNA quantity, DNA damage and heat shock protein gene expression as physiological stress markers in chickens. Poult. Sci., 91: 829-836. DOI: $10.3382 /$ ps.2011-01904

Sohn, S.H. and V.K. Subramani, 2014. Dynamics of telomere length in the chicken. World's Poultry Sci. J., 70: 721-735. DOI: 10.1017/S0043933914000804

Swanberg, S.E., T.H. O'Hare, E.A. Robb, C.M. Robinson and H. Chang et al., 2010. Telomere biology of the chicken: A model for aging research. Exp. Gerontol., 45: 647-654. DOI: 10.1016/j.exger.2010.04.002

Takubo, K., J. Aida, N. Izumiyama-Shimomura, N. Ishikawa and M. Sawabe et al., 2010. Changes of telomere length with aging. Geriatr. Gerontol. Int., 10: 197-206. DOI: $10.1111 / \mathrm{j} .1447-0594.2010 .00605 . x$

Wang, A.L., T.J. Lukas, M. Yuan and A.H. Neufeld, 2010. Age-related increase in mitochondrial DNA damage and loss of DNA repair capacity in the neural retina. Neurobiol. Aging, 31: 2002-2010. DOI: 10.1016/j.neurobiolaging.2008.10.019

Wang, C., D. Jurk, M. Maddick, G. Nelson and C. Martin-Ruiz et al., 2009. DNA damage response and cellular senescence in tissues of aging mice. Aging Cell, 8: 311-23. DOI: 10.1111/j.1474-9726.2009.00481.x

Xu, M., X.B. Wu, P. Yan and H. Zhu, 2009. Telomere length shortens with age in Chinese alligators (Alligator sinensis). J. Applied Anim. Res., 36: 109-112. DOI: 10.1080/09712119.2009.9707042 